\title{
The SESAMI evaluation of employment support in the UK: Background and baseline data
}

\section{THE SESAMI RESEARCH TEAM ${ }^{1}$ \& PRACTICE PARTNERSHIP ${ }^{2}$}

\section{${ }^{1}$ Research team:}

Justine Schneider, University of Nottingham and Nottinghamshire Healthcare Trust; Jenny Secker, Anglia Ruskin University and South Essex Partnership NHS Trust;

Bob Grove, Sainsbury Centre for Mental Health;

Mike Floyd, City University, London;

Jan Slade, University of Durham;

Melanie Boyce, Anglia Ruskin University;

Robyn Johnson, City University, London, UK

and

${ }^{2}$ Practice partners:

Department of Work and Pensions;

Mental Health Matters;

Remploy;

Richmond Fellowship Employment and Training;

Shaw Trust; South West London \& St George's Mental Health

NHS Trust

\section{Abstract}

\section{Aims:}

This study evaluates real world employment support for people with severe mental health problems in the UK. Given a policy context which promotes social inclusion and welfare to work, we wanted to find out about typical employment services and their effects on people with mental health problems.

\section{Method:}

A case study design was adopted, incorporating qualitative and quantitative interviews with staff and users of each service. After screening for severity, 182 individuals met our inclusion criteria for current use of the services. They were interviewed about their current engagement with support services, their employment and job satisfaction if employed. Measures of self esteem, hope/optimism and job satisfaction were taken as outcomes.

\section{Results:}

We report here associations between the outcome measures and: current working status; support from the agency; and demographic features at baseline. People who were working had higher outcome scores than those who were in work preparation or training. People working with support had higher job satisfaction.

\section{Conclusions:}

The study highlights the methodological issues raised by doing real world research. These findings were generated by heterogeneous interventions in non-experimental settings. Despite this, they tend to support previous evidence in favour of early placement and ongoing support in work.

\section{Declaration of interest:}

This study was financed by the European Social Fund and the six practice partners made contributions in kind.

Keywords: Severe mental health problems, work, supported employment, welfare to work 


\section{Introduction}

People with severe mental health problems remain the disability group least likely to be in work. Despite developments in disability policy and practice, their rate of employment, at only $20 \%$, may be compared to people with learning disabilities at $23 \%$ and people who have problems seeing at 52\% (Labour Force Survey for Winter, 2004). This paper reports on a naturalistic study which investigated the situation of 182 people with mental health problems who were receiving agency support to help them get or keep jobs. It is pertinent to the proposed new benefits regime in the UK, under which it appears that these individuals will be faced with two choices: either to opt for exemption on the grounds of severity of impairment, or to pursue their rights to work, taking advantage of the available support mechanisms. Details of the existing UK benefits regime in relation to eight other countries' systems can be found in Mitra (2006), while Lunt and Thornton (1993) offer a transnational perspective from an earlier time point.

There is extensive evidence about what works in helping people with mental health problems get jobs (Bond, 2004; Crowther et al., 2001; Lehman, 2002; Schneider, 2005a; Twamley, 2003). Most of the studies generating this evidence come from the USA, so it is important to bear in mind that service users in United States and the UK face different incentives to working. For one thing, health insurance coverage in the UK does not depend on being in work as it does in the US (MacDonald-Wilson et al., 2003). For another, under the current system, people on Income Support are be penalised for working by having the amount earned over £20 per week deducted from their benefits. That said, the research evidence derived from experimental studies leaves no doubt that Individual Placement and Support (IPS) is the way forward in enabling people with mental health problems to get back to work. A key feature of the delivery of IPS in the US context is its "integration" with mental health services, meaning that vocational specialists there work closely with community mental health teams. In addition to IPS, within a system which emphasizes placing people in real jobs as quickly as possible, focussed psychological support and workplace skills training may foster longer job retention (Schneider, 2005a).

\section{Background}

Since coming to power in 1997, UK New Labour government policy has been dominated by the Welfare to Work agenda. Reducing the numbers of social security benefit claimants of working age has been an important economic and policy target, with a series of programmes targeted at disabled people, particularly those in receipt of Incapacity Benefit (IB), together with lone parents and the young unemployed. The Disability Discrimination Acts 2000 and 2005 establish the employment rights of people with disabilities and specify employers' obligations to ensure equality of opportunities. In the 2005 Act the definition of mental health problems was changed to cover many more people with mental health problems.

The Green Paper outlining plans for welfare benefit reforms, A New Deal for Welfare: Empowering People to Work (Department of Work and Pensions (DWP), January, 2006) is the latest in a series of policy initiatives and programmes designed to move people off welfare and back into the labour market. One of these programmes, New Deal for Disabled People (NDDP), is delivered through advisers known as job brokers to individuals with health or disability related barriers to labour market entry. It aims to provide career advice, practical support and guidance through the benefits maze. Another programme, Workstep - successor to the Supported Placement Scheme - is designed to help people who face more complex barriers, and can provide training and ongoing support to the employer as well as the employee. The most recent initiative, the Pathways to Work pilots, is aimed mainly at new claimants of Incapacity Benefit (IB) and supplements the personal advisor approach with condition management advice provided by the NHS and a cash incentive of $£ 40$ per week "return to work" payment. NDDP, Workstep and all other Jobcentre Plus commissioned programmes are included in the "Choices" package in Pathways to Work.

A significant proportion (40\%) of current IB claims are attributed to mental health problems and one third of new claimants cite mental ill health as the reason for their disability. The majority of these claims will be due to the most prevalent mental health problems, mild-to- 
moderate depression or anxiety disorders, which can often be transient. While the published evaluations of existing government programmes seldom differentiate outcomes for people with specific types of disability, there is an indication from the NDDP evaluation that people with mental health problems, once placed, were more likely than other disability groups to lose their jobs (DWP, 2004). In relation to clients' views of the benefits of Workstep, Meah and Thornton (2005) found that people "with mental health conditions also indicated that it was important to have the continuity of a designated support worker" (p. 38). A qualitative study of the role of Pathways to Work personal advisers found that 'moderate to severe' mental health issues were judged to be among the more difficult cases and that advisors sometimes found it desirable to waive or defer a work focussed interview on grounds of mental illness (Dickens et al., 2004).

Using approaches based on the Pathways to Work model, the Green Paper proposes to reduce the number of people dependent on benefits due to disability by 1 million over ten years, by introducing vocational advisors into GP surgeries and creating partnerships of health, local authority and employers. All disabled people, including those with mental health problems, will face a stricter benefits environment, structured to reward efforts made towards gaining employment.

- Existing claimants will retain their benefits but their situations will be reviewed periodically for employment potential;

- If they try work and cannot sustain it, benefit levels will be protected;

- From 2008, the Employment \& Support Allowance will be paid to new claimants in return for work-related activity (job hunting, work experience etc.);

- There should be no assumption that any person is exempted from work by their diagnosis alone, and

- People whose functioning is severely affected will receive benefits without "conditionality"-i.e., without having to demonstrate work-related activity.

The latter two points sum up the dilemma for people with severe mental health problems and their carers: whether to claim their entitlements to the support necessary to get and keep a job or to seek exemption on grounds of severity of impairment. The support needed to get work may be considerable because of the particular disadvantages faced by people with severe mental health problems, many of which have not been altered by policy. These disadvantages include structural and attitudinal barriers; stigma, ignorance and fear of mental illness. Employers are reluctant to take on people with mental illness, while colleagues may be hostile or unsympathetic. In addition to tangible impairments to skills and stamina resulting from the illness and its treatment, stigma and prejudice undermine people's confidence, distort their perception of their own capacity to work, and may discourage them from seeking a job. Anti-discrimination legislation, however comprehensive, can only come into play once a person has applied for a job. These and other issues have been addressed by the Social Exclusion Unit's Report Mental Health and Social Exclusion (ODPM, 2004a) and in Action on Mental Health: A Guide to Promoting Social Inclusion (ODPM, 2004b).

At the same time, little is known about what it takes in practice to help people with severe mental health issues get and keep work in a UK context. In the UK at present, people with mental health problems can obtain support into work from a range of sources. Specialized help for disabled people is available from a number of agencies which are contracted by the DWP to deliver NDDP and Workstep programmes. Mental health and generic disability organizations in the voluntary sector hold a high proportion of these DWP contracts, with some local authorities also running employment programmes through this funding source. Support into work for individuals is also available directly through the DWP's network of local offices, Jobcentre Plus, although in recognition that their in-house expertise on mental health issues is limited, specialist support is increasingly contracted out by local offices. Thirdly, there are some NHS-based initiatives which work from both an employment and a clinical perspective to enable patients recovering from mental health problems to fulfil their occupational potential (Schneider, 2005b). 


\begin{abstract}
Aims
Our overall aim was to study people with mental health problems who were being supported in getting and keeping employment in real world settings, rather than in experimental conditions. Based on previous research (e.g., Bond, 2004) we hypothesized that people with mental health problems would have higher self-esteem and higher hope/optimism if they were in paid work than if they were in training or work preparation. In addition we wanted to obtain a profile of users of supported employment for people with severe mental health problems, their age, gender, ethnicity, employment status and job satisfaction where applicable, and in relation to the different agencies and funding programmes in operation at the time. Is specialist mental health support more stigmatizing than generic provision? We are not aware of any other study that compares the impact on individual hope and self-esteem of different types of programme (governmental and non-governmental). Moreover, evaluations of UK government programmes seldom investigate their impact on people with mental health problems as a distinct group. With the cross-sectional, baseline data we aimed also to begin to explore these issues.
\end{abstract}

\title{
Method
}

We adopted a case-study approach to evaluating the effectiveness of employment support for people with severe mental health problems. Within each participating agency we identified a cohort of current users, whom we followed up over 12 months. Ethical approval was obtained for the study from the North West Multi-centre Research Ethics Committee. Research governance approvals were granted by the relevant NHS Trusts where applicable.

We recruited as partners in the study six agencies which, to our knowledge, were amongst the largest specialist mental health providers in the UK. They included one mental health trust, the DWP, one private business, and three voluntary organizations.

Working outside a clinical context, our first challenge was to select an appropriate sample. We set as our inclusion criterion the presence of severe and enduring mental health problems, judged as a score of more than 3 in the responses to the items shown in Box 1 . With the agencies' assistance, everyone on their books described as having a mental health problem was invited to participate in the study by letter. Of the 888 people contacted, 340 replied and 48 declined to participate. The 292 who agreed to participate completed a brief screening questionnaire and 270 met our criterion. Thirty-two of these people decided to withdraw from the study and 27 did not respond to further contact. In this way, 211 participants were recruited and interviewed.

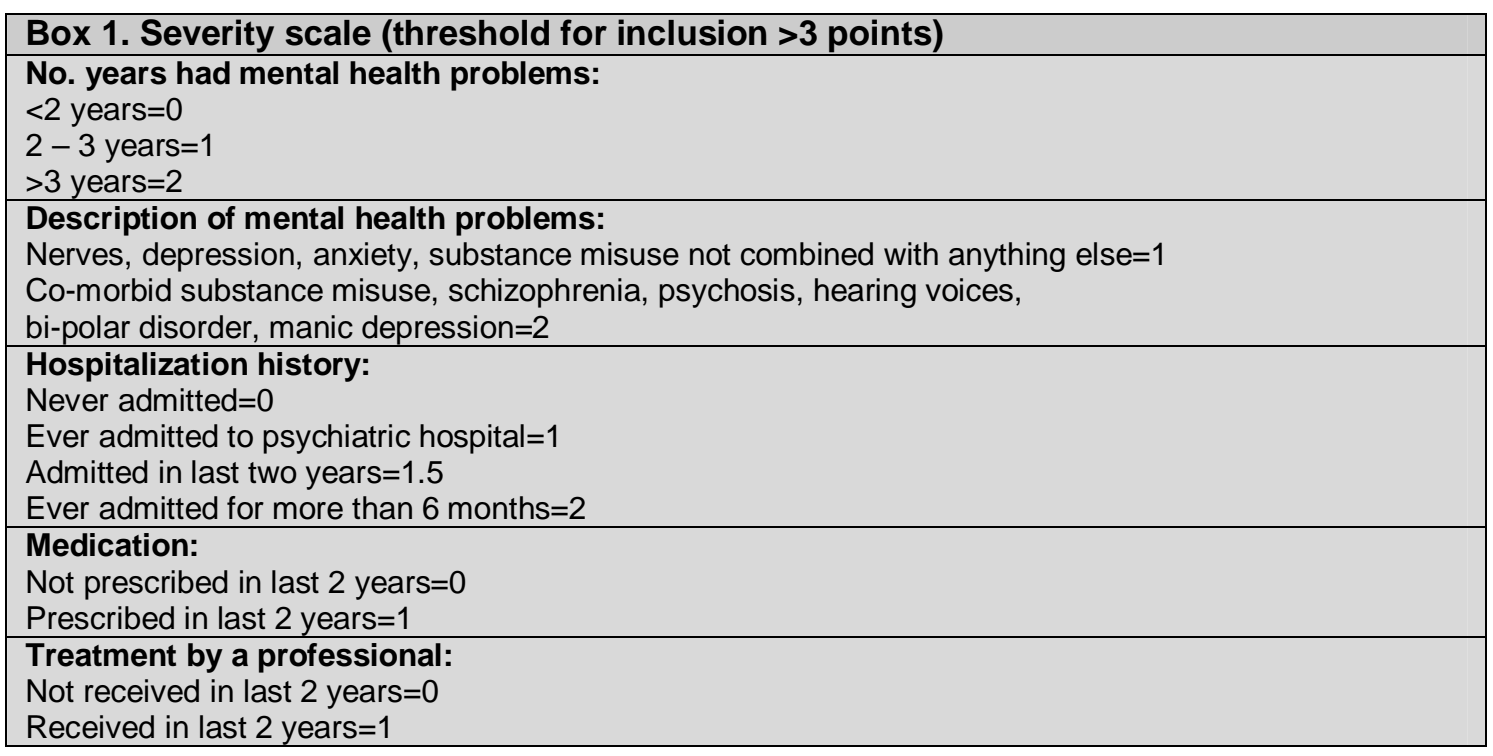


Participants were interviewed between September 2004 and March 2005 (Baseline). Six telephone interviews were conducted where a face-to-face meeting was logistically difficult. The interview included background information about the service user, details of their employment or training, income and benefits received, an inventory of the health and social care services they were using, ratings of their self-esteem (Rosenberg, 1979, included in the "Making Decisions" scale of empowerment by Sciarappa et al., 1994), and a rating of hope or optimism (Herth, 1992) which is taken here to indicate morale. This scale elicits levels of agreement with statements like: "I have deep inner strength"; "I have a sense of direction" and "I feel scared about my future". For those people in work, we administered the Minnesota Satisfaction Questionnaire (Weiss et al., 1967). Baseline data from these measures are reported here.

In-depth interviews were held with a sub-sample of people in employment about 6 months later and all participants were followed up after 12 months. Managers of the agencies were interviewed to explore the ways in which they delivered their services. These data are reported separately (Boyce et al., forthcoming).

We tested our hypotheses concerning self esteem and hope or optimism using boxplots and $t$-tests of independent means. We also investigated the possibility of differences on these scales between people on different government programmes, Workstep and NDDP, to find out whether one appears to suit people with mental health problems better than the other.

\section{Findings}

Of those interviewed, 182 people who met our severity criterion were actively engaged with one of the six agencies. They are treated here as one group of clients with severe mental health problems receiving different degrees of support into employment. The mean severity score was 6.12 (standard deviation 1.24, range $3.5-8$ ). Table I describes the final sample in terms of gender and the agency where they were known. Fifty-eight per cent of the sample was male. Eighty per cent of the sample was White British, $11 \%$ Asian including Pakistani, Bangladeshi and Indian, 3\% Black British (born in UK), 3\% White European and 3\% "other ethnic groups". None of the clients in the baseline sample was of Black African or African Caribbean ethnic origin. The average age in 2005 was 42.24 (SD 9.99,

range $21-67)$.

\section{Work and earnings}

Fifty-two of the baseline sample were in paid employment in competitive, real world jobs (referred to here as "open" employment) at the time of interview (29\%) and a further eight individuals $(4 \%)$ were working, but in settings that were restricted to people with disabilities (sheltered work). These people were excluded from analyses comparing people in employment to people not in work. A proportion of the sample was in a work-related placement (17 people, 9\%), but the remaining 105 (58\%) were in a pre-vocational situation; searching for a job, receiving some kind of work preparation, in training, or still contemplating the move into work. At interview, 14 of the latter group regarded themselves as having been discharged by the agency, and nine of the people in open employment regarded themselves as discharged. As far as they were concerned, their support from the agency had ended, even though the agency had contacted them on our behalf to invite them to participate in the study.

One interviewee declined to give information about their financial situation, but the benefits and tax allowances claimed by the rest of the sample are shown in Table II. Most people who were not in paid employment claimed housing and council tax benefits, as well as Incapacity Benefit. Disabled Living Allowance was claimed by half of this group, and by one quarter of people in paid work. The latter group were more likely to be claiming Working Tax Credit, and a few were on Disabled Persons Tax Credit. Table II shows that the working group used more tax credits and allowances while the non-working group used more benefits. At Time 1, of 17 people in receipt of Incapacity Benefit and Income Support, only one was in paid employment. 


\begin{tabular}{|l|c|c|c|}
\hline \multicolumn{3}{|c|}{ Table I. Baseline sample gender by agency } \\
\hline & \multicolumn{2}{|c|}{ Gender } & \\
\hline Agency & Male & Female & Total \\
& & & \\
\hline Jobcentre + & 13 & 6 & 19 \\
& $68 \%$ & $32 \%$ & $100 \%$ \\
\hline Mental Health Matters & 13 & 12 & 25 \\
& $52 \%$ & $48 \%$ & $100 \%$ \\
\hline Remploy & 17 & 13 & 30 \\
& $57 \%$ & $43 \%$ & $100 \%$ \\
\hline Richmond Fellowship Employment \& & 21 & 22 & 43 \\
Training & $9 \%$ & $51 \%$ & $100 \%$ \\
\hline Shaw Trust & 11 & 4 & 15 \\
& $73 \%$ & $27 \%$ & $100 \%$ \\
\hline South West London \& St. George's & 30 & 20 & 50 \\
& $60 \%$ & $40 \%$ & $100 \%$ \\
\hline All & 105 & 77 & 182 \\
& $58 \%$ & $42 \%$ & $100 \%$ \\
\hline
\end{tabular}

\begin{tabular}{|l|c|c|c|}
\hline \multicolumn{4}{|c|}{ Table II. Benefits profile (one person declined to give details). } \\
\hline Benefits status & $\begin{array}{c}\text { Not working } \\
\mathbf{N = 1 2 5} \\
\%\end{array}$ & $\begin{array}{c}\text { Working } \\
\mathbf{N = 5 5} \\
\%\end{array}$ & $\begin{array}{c}\text { Chi-squared test } \\
\mathbf{p}\end{array}$ \\
\hline Receive any benefits & 96.8 & 40.0 & $<0.001$ \\
\hline Job Seekers Allowance & 5.6 & 18 & $\mathrm{NS}$ \\
\hline Income Support & 40.8 & 3.6 & $<0.001$ \\
\hline Statutory Sick Pay & 0.8 & - & $\mathrm{NS}$ \\
\hline Incapacity Benefit & 57.6 & 8.2 & $<0.001$ \\
\hline Disabled Living Allowance & 49.6 & 5.5 & 0.003 \\
\hline Carer's Allowance & 0.8 & - & $\mathrm{NS}$ \\
\hline Other benefits & 2.4 & 3.6 & $\mathrm{NS}$ \\
\hline Disabled Person's Tax Credit & 2.5 & 9.7 & $\mathrm{NS}$ \\
\hline Working Tax Credit & 2.5 & 48.4 & $<0.001$ \\
\hline Child Tax Credit & 6.3 & 12.9 & $\mathrm{NS}$ \\
\hline Housing Benefit & 68.4 & 12.9 & $<0.001$ \\
\hline Council Tax Benefit & 67.1 & 22.6 & $<0.001$ \\
\hline I have enough money to live on & 58.7 & 67.9 & $\mathrm{NS}$ \\
\hline
\end{tabular}

The mean severity score for those people in paid work (6.069) was not significantly lower than that for the people not in paid work $(6.138, p=0.735)$. However, four of the nonworking group had been treated as psychiatric inpatients in the previous 3 months, for an average of 11 days. These were the only people in the sample $(2 \%)$ who had psychiatric admissions in the three months preceding baseline interviews. To place this finding in context, $30 \%$ of our sample had been inpatients in the previous 2 years, and $72 \%$ had been inpatients at some time in their lives.

The people in work had a variety of paid jobs. Using the Standard Occupational Classification 2000 (National Statistics, 2005), the largest proportion worked in entry level jobs and personal service occupations, such as catering assistants and care workers. However, there was a fair representation of sales, administration, technical and professional occupations among the sample (Table III). The mean number of hours worked in these jobs was 26.02 (SD 12.95, $n=55)$. Of these people $28(51 \%)$ could be considered part-time, as they were working 22 hours or less. Average weekly earnings for the 43 people in open employment who were able 
to tell us this was $£ 148.70$ (SD 103.88). The national average part time wage in 2005 was $£ 164.20$ for all types of employee. By comparison, full time employees earned £517 per week (ONS, 2005).

\begin{tabular}{|l|c|}
\hline Table III. Occupational groups. & Number \\
\hline & 1 \\
\hline Managers and senior officials & 5 \\
\hline Professional occupations & 6 \\
\hline Associate professional and technical occupations & 9 \\
\hline Administrative and secretarial occupations & 4 \\
\hline Skilled trade occupations & 12 \\
\hline Personal service occupations & 5 \\
\hline Sales and customer service occupations & 3 \\
\hline Process, plant and machine operatives & 14 \\
\hline Elementary occupations & \\
\hline
\end{tabular}

\section{Self-esteem and hope or optimism}

Our hypothesis was that working would be associated with higher self-esteem and better morale, regardless of the type of agency where the individual was being supported. To perform this analysis for supported employees, we excluded people who told us that they had been discharged by the agency or that they were working without support from the agency. This left 159 in the sample, 42 people in open, paid employment, 92 not working and 25 in placements or sheltered work, all actively receiving support from one or another of the agency partners in our study. Those people in work had been with the agency for 35.7 months (SD 61.42) on average, significantly less than those people who were not working (mean 133.99, SD 14.46, $p=0.02$ ). Table IV gives the means for these three groups in terms of the severity score, years with mental health problems and outcome measures. Analysis of variance indicates that the three groups are homogenous with respect to severity and years with mental health problems, but not in relation to hope or optimism and self-esteem scores.

Combining the placement/sheltered group with the non-working group, we compared those people in work using t-tests of independent means. We found that people in open, supported employment had significantly higher mean scores on both measures. Their average hope and optimism score was 36.2 as compared to $32.83(p<0.001)$ and their self esteem score was on average 23.44 as compared to $21.87(p=0.019)$. When the people who had been discharged by the agency but were still working were included together with the supported employees, mean scores for both hope and self-esteem fell for the working group, although the differences remained statistically significant when compared to the nonworking group ( $p=0.004$ for hope/optimism and $p=0.035$ for self-esteem).

Table IV. Severity and outcome scores by current employment status.

\begin{tabular}{|l|c|c|c|c|c|c|c|c|}
\hline \multicolumn{2}{|c|}{ Open work } & \multicolumn{2}{c|}{ Placement/sheltered } & \multicolumn{2}{c|}{ Not working } & \multicolumn{2}{c|}{ ANOVA } \\
\hline $\begin{array}{l}\text { Summary } \\
\text { severity } \\
\text { score }\end{array}$ & 42 & $6.14(1.20)$ & 25 & $6.32(1.34)$ & 92 & $6.09(1.24)$ & 0.35 & 0.708 \\
\hline $\begin{array}{l}\text { Years with } \\
\text { MHP }\end{array}$ & 41 & $13.39(10.74)$ & 23 & $14.13(7.38)$ & 90 & $11.93(8.90)$ & 0.70 & 0.498 \\
\hline $\begin{array}{l}\text { Herth total } \\
\text { score }\end{array}$ & 30 & $36.20(5.19)$ & 23 & $33.13(4.14)$ & 75 & $32.73(4.19)$ & 6.72 & 0.001 \\
\hline Self-esteem & 32 & $23.44(3.41)$ & 22 & $22.73(3.33)$ & 76 & $21.62(3.13)$ & 3.85 & 0.023 \\
\hline
\end{tabular}


There is not scope in this paper to address the similarities and differences of the six partner agencies, their methods and approaches in any detail. Our website, http://www.sesami.org.uk provides links to each agency's own website for further details. Table $V$ shows the mean severity, length of illness and outcome scores by programme: Workstep, NDDP and "other". In some agencies, clients could be on any of these types of funding but in others only core funding, which includes NHS initiatives, applied (classed together as "other"). This table indicates that in terms of our severity score the three groups were similar to each other. The analysis shows that for Workstep clients more years had elapsed since their illness was diagnosed, but they were not more severely affected than the other two groups. None of the three groups differed in terms of outcome measures of self-esteem or hope and optimism.

Table V. Programme funding by severity and outcome indicators

\begin{tabular}{|l|c|c|c|c|c|c|c|c|}
\hline & \multicolumn{2}{|c|}{ Workstep } & \multicolumn{2}{|c|}{ NDDP } & \multicolumn{2}{c|}{$\begin{array}{c}\text { Other/core } \\
\text { funding }\end{array}$} & & \\
\hline & $\boldsymbol{n}$ & Mean (SD) & $\boldsymbol{n}$ & Mean (SD) & $\boldsymbol{n}$ & Mean (SD) & $\boldsymbol{F}$ & $\boldsymbol{p}$ \\
\hline $\begin{array}{l}\text { Summary } \\
\text { severity score }\end{array}$ & 28 & $5.91(1.15)$ & 43 & $5.85(1.20)$ & 88 & $6.35(1.26)$ & 0.77 & 0.464 \\
\hline Years with MHP & 26 & $14.00(9.18)$ & 42 & $11.29(9.58)$ & 86 & $12.91(9.06)$ & 3.04 & 0.050 \\
\hline Herth total score & 24 & $34.04(4.95)$ & 30 & $34.77(5.04)$ & 74 & $33.01(4.31)$ & 1.67 & 0.192 \\
\hline $\begin{array}{l}\text { Self-esteem - } \\
\text { Self Efficacy } \\
\text { Factor }\end{array}$ & 24 & $21.58(3.20)$ & 35 & $22.34(3.54)$ & 71 & $22.44(3.23)$ & 0.61 & 0.543 \\
\hline
\end{tabular}

\section{Job satisfaction}

The total score on the job satisfaction scale was only obtained for 46 people, although the component scale extrinsic satisfaction had 53 respondents and intrinsic satisfaction had 48. Table VI shows the correlations between the job satisfaction scales and our outcome measures. It indicates that intrinsic satisfaction and, consequently, the total score, correlate with hope and optimism. Intrinsic satisfaction is less highly correlated with self-esteem and the correlation between general satisfaction and self esteem does not attain statistical significance.

\begin{tabular}{|c|c|c|c|c|}
\hline & $\begin{array}{c}\text { Herth } \\
\text { total score }\end{array}$ & Self-esteem & $\begin{array}{l}\text { MSQ: Intrinsic } \\
\text { Satisfaction }\end{array}$ & $\begin{array}{c}\text { MSQ: General } \\
\text { Satisfaction }\end{array}$ \\
\hline $\begin{array}{l}\text { Self-esteem Factor } \\
\text { Pearson Correlation } \\
\text { Sig. (2-tailed) } \\
n\end{array}$ & $\begin{array}{l}.697\left(^{* \star}\right) \\
.000 \\
136\end{array}$ & & & \\
\hline $\begin{array}{l}\text { MSQ: Intrinsic Satisfaction } \\
\text { Pearson Correlation. } \\
\text { Sig. (2-tailed) } \\
\text { N }\end{array}$ & $\begin{array}{l}.448\left(^{(*}\right) \\
.003 \\
41\end{array}$ & $\begin{array}{l}.345\left(^{*}\right) \\
.025 \\
42\end{array}$ & & \\
\hline $\begin{array}{l}\text { MSQ: General Satisfaction } \\
\text { Pearson Correlation. } \\
\text { Sig. (2-tailed) } \\
\text { n }\end{array}$ & $\begin{array}{l}.430\left(^{(*}\right) \\
.006 \\
39\end{array}$ & $\begin{array}{l}.269 \\
.094 \\
40\end{array}$ & $\begin{array}{l}\left..8811^{(* *}\right) \\
.000 \\
46\end{array}$ & \\
\hline $\begin{array}{l}\text { MSQ: Extrinsic Satisfaction } \\
\text { Pearson Correlation. } \\
\text { Sig. (2-tailed } \\
\text { n }\end{array}$ & $\begin{array}{l}.252 \\
.100 \\
44\end{array}$ & $\begin{array}{l}.069 \\
.659 \\
43 \\
\end{array}$ & $\begin{array}{l}\left..573^{(* *}\right) \\
.000 \\
46\end{array}$ & $\begin{array}{l}.879\left(^{(* *}\right) \\
.000 \\
46\end{array}$ \\
\hline
\end{tabular}


Analysis of variance indicated that none of the job satisfaction scales differed by programme funding. We also looked at whether people were actively involved with the agency concerned. Eight people in work for whom we obtained job satisfaction scores told us that they had been discharged by the agency. We found that these people had significantly lower extrinsic satisfaction scores (17.25) than the 38 who were still in contact with the agency (21.68, $p=0.027$ ). This may be taken to indicate that people with ongoing support from the agency had higher job satisfaction, but there is the possibility that the rupture with the agency was associated with prior job dissatisfaction. Follow-up data should enable us to discern the direction of causality.

\section{Discussion}

These preliminary findings describe a substantial number of people with severe mental health problems who are working or have the potential to work. They are an important group in relation to the goals of the Green Paper on benefit reforms. Some methodological issues can be drawn from the initial findings, and these are relevant to the provision and evaluation of employment opportunities. In particular, our experience of undertaking this naturalistic study highlights several contrasts with the RCT design on which much of the international research to date has been based, and in which the focus is on the evaluation of highly specified interventions.

The first issue is identifying people with severe mental health problems. Although agencies generally have a record of the client's main disability, this was not reliable for our purpose. In particular, they seldom differentiate between mild, moderate and severe mental health problems. Of the 888 people whom we contacted explaining that we were interested in severe mental health issues, fewer than half (340) replied and some of these will have excluded themselves because their impairment did not meet our severity criterion. Our second screening for severity ruled out more respondents. We ultimately interviewed 211 , less than one quarter of all the clients listed as having mental health problems by the agencies. It appears that the agencies' caseloads, taken together, are dominated by people who do not have severe mental health problems, although this may not be true for individual agencies.

Second, there is a problem in identifying who is actively involved with an agency. Careful review of respondents' own opinions on this matter showed that the agency records were sometimes not reliable. In some cases, people had remained "on the books" long after all contact had ceased. In others, relatively new clients told us that they had not yet received any input from the agency. If no active involvement can be demonstrated, it would be erroneous to judge the agencies' effectiveness in relation to these individuals.

The lack of contact between client and agency was sometimes explained. On the clients' part, reasons might include exacerbation of a mental health problem, or the fact that they found work through another route. In some cases, the agency deemed the person "not work ready", and they entered a suspended phase that was difficult to define because it was not clear who should re-initiate contact. Organizational problems in the agency, such as office closures or staff turnover, were a further explanation given for lack of contact.

Partly due to the logistical difficulties of the study and partly due to the complications outlined above, the baseline dataset is marred by missing data. This affects the numbers of cases available whose summary scores can be reported. Here, we make no adjustments to the data to compensate for missing cases, but this may be required to complete more detailed analyses at follow-up.

Despite these difficulties, and the scarcity of specialist support for people with mental health problems in the UK, the sample which we achieved is substantial, and the detailed information collected from them is unprecedented in this country. For the first time, it permits us to profile a sizeable group of people with severe mental health problems at the stage where employment support is likely to make a critical difference to their outcomes. 
The research evidence on supported employment from North America indicates that placing people in work and supporting them is more effective than extended preparation prior to placement (Bond \& Dincin, 1986). This evidence, combined with the logic of enabling people to reduce their dependency on benefits as far as possible, are reflected in supported employment principles which stress "placement, then training" as opposed to "training, then placement" (O'Bryan et al., 2000). Notwithstanding, this study found that only a minority of people using supported employment services were in work, most were in some preparatory situation. Yet, in keeping with the preference for the "placement, then training" approach, our preliminary findings tend to support an association between higher self-esteem and real work, and between higher morale and real work. Of course, these are cross-sectional comparisons, so the direction of causality remains unclear.

\section{Conclusion}

As a pioneering study of the operation of employment support for people with mental health problems, the SESAMI study has relevance for the development of services for people with mental health problems, and it is timely in the light of disability policy developments in the UK. Most of the evidence hitherto reported on supported employment derives from a North American context and from studies where the intervention is the highly specific IPS model. Here, we present our findings as a naturalistic picture of employment support in relation to individuals with severe mental health problems in England. This analysis indicates that, in relation to six major providers of employment support:

- Provision is dominated by models funded by government programmes for disabled people in general.

- Most beneficiaries are men, as is often found in studies of employment interventions.

- Those in work are doing a wide range of jobs.

- Most people with severe mental health problems "on the books" of these programmes are in pre-work situations.

Although the direction of causality cannot be assumed:

- Those people in open employment are more optimistic and have higher self-esteem.

- People receiving ongoing support are more satisfied in their work.

This status quo is the context within which benefit reforms will impact on people with severe mental health problems. The role of government programmes which address disability, but not mental illness in particular, is important in so far as this is where service users and providers must look for future opportunities. The high proportion of men is not surprising in the context of employment research. It may reflect a number of factors, both extrinsic and intrinsic to the provider agencies. Still, the UK public sector employer duty on gender equality, which comes into force in 2007, may be an issue for providers. The range of jobs found challenges the prejudice that employment opportunities for people with mental health problems are limited to menial jobs. The high proportion of people who were found not to be in real work suggests that, despite the agency provision, the obstacles to work confronting people with mental health problems may require particular attention. The proposed changes to welfare benefit entitlements will require regular reviews of ability to work and will make some benefits conditional on the steps taken to procure employment. If people with mental health problems are not to seek exemption from conditionality on the grounds of severity, which would of course be contrary to the principles and values of social inclusion, they will require expert support to obtain the psychological and social advantages offered by paid employment.

Results from the follow-up study will enable us to make inferences about changes in employment and benefit status over twelve months. These preliminary findings suggest that, in keeping with the evidence base, getting people into jobs should have beneficial outcomes with respect to self-esteem and hope/optimism, while continuing to support them may impact on job satisfaction. 


\section{Acknowledgements}

The authors gratefully acknowledge the participation of interviewees and agency staff in this study, and also the constructive contributions made by Miles Rinaldi, Kevin Tunnard and two anonymous reviewers.

\section{References}

Bond, G., \& Dincin, J. (1986). Accelerating entry into supported employment for persons with severe psychiatric disabilities. Rehabilitation Psychology, 40, $91-111$.

Bond, G. (2004). Supported employment: Evidence for an evidence-based practice. Journal of Psychiatric Rehabilitation, 27, 345 - 359.

Boyce, M., Secker, J., Floyd, M., Grove, B., Johnson, R., Schneider, J., \& Slade, J. (forthcoming). Factors influencing the delivery of evidence-based supported employment in England. Psychiatric Rehabilitation Journal.

Crowther, R., Marshall, M., Bond, G., et al. (2001). Helping people with severe mental illness to obtain work: Systematic review. British Medical Journal, 322, $204-208$.

Department of Work and Pensions (2006). A new deal for welfare: Empowering people to work $\mathrm{Cm} 6730$.

DWP (2004). NDDP First Synthesis Research Report: Executive Summary. Accessed 24 February 2006 from: http://www.dwp.gov.uk/jad/2004/199rep.pdf

Dickens, S., Mowlam, A., \& Woodfield, K. (2004). Incapacity Benefit Reforms - the personal adviser role \& practices. Prepared for the Department of Work and Pensions. London: NatCen. Accessed 24 February 2006 from: http://www.dwp.gov.uk/jad/2004/212rep.pdf

Herth, K. (1992). Abbreviated instrument to measure hope: Development and psychometric evaluation. Journal of Advanced Nursing, 17, 1251 - 1259.

Labour Force Survey for Winter (2004). Accessed 13 January 2006 from: http://www.shaw-trust.org.uk/page/6/89

Lehman, A. F., Goldberg, R., Dixon, L. B., McNary, S., Postrado, L., Hackman, A., \& McDonnell, K. (2002). Improving employment outcomes for persons with severe mental illnesses. Archives of General Psychiatry, 59, 165 - 172.

Lunt, N., \& Thornton, P. (1993). Employment policies for disabled people: A review of legislation and services in fifteen countries, Research Series No. 16, Employment Department: Sheffield.

MacDonald-Wilson, K. L., Rogers, E. S., Ellison, M. L., \& Lyass, A. (2003). A study of the social security work incentives and their relation to perceived barriers to work among persons with psychiatric disability. Rehabilitation Psychology, 48, $301-309$.

Meah, A., \& Thornton, P. (2005). Desirable outcomes of WORKSTEP: User and provider views. Department for Work and Pensions Research Report No 279, Corporate Document Services.

Mitra, S. (2006). Learning from others: Temporary and partial disability programs in nine countries: What can the United States learn from other countries?. Program for Disability Research, New Bruinswick, New Jersey. Accessed 28 April 2006 from: http://www.dri.uiuc.edu/research/p04-12h/policy note final.doc

National Statistics (2005). Accessed 20 March 2006 from: http://www.statistics.gov.uk/methods quality/ns sec/soc2000.asp

O'Bryan, A., Simons, K., Beyer, S., \& Grove, B. (2000). A framework for supported employment. Policy Consortium for Supported Employment, York: YPS for the Joseph Rowntree Foundation.

ODPM (2004a). Mental health and social exclusion: Social Exclusion Unit Report. London: Office of the Deputy Prime Minister.

ODPM (2004b). Action on mental health: A guide to promoting social inclusion. London: Office of the Deputy Prime Minister.

ONS (2005). Annual survey of hours and earnings. Accessed 20 March 2006 from: http://www.statistics.gov.uk/StatBase/Product.asp?vlnk=14203

Rosenberg, M. (1979). Conceiving the self. New York: Basic Books.

Sciarappa, K., Rogers, E. S., \& Chamberlin, J. (1994). A consumer constructed empowerment scale to measure empowerment among users of mental health services. Psychiatric Services, 48, 1042 - 1047. 
Schneider, J. (2005a). Getting back to work: What do we know about what works? In B. Grove, J. Secker \& P. Seebohm (Eds.), New thinking about employment and mental health (pp. 37 - 49). Oxford: Radcliffe.

Schneider, J. (2005b). Employment support in the UK: Where are we now? In B. Grove, J. Secker \& P. Seebohm (Eds.) New thinking about employment and mental health. (pp. 51 - 59). Oxford: Radcliffe.

Twamley, E., Jeste, D., \& Lehman, A. (2003). Vocational rehabilitation in schizophrenia and other psychotic disorders: A literature review and meta-analysis of randomized controlled trials. Journal of Nervous and Mental Disease, 191, 515 - 523.

Weiss, D. J., Dawis, R. V., England, G. W., \& Lofquist, L. H. (1967). Manual for the Minnesota Satisfaction Questionnaire. Industrial Relations Center, University of Minnesota. 